\title{
THE BLOOD URIC ACID IN DISEASE
}

\author{
By EDWIN P. JORDAN AND DOROTHY GASTON \\ (From the Department of Medicine of the University of Chicago, Chicago)
}

(Received for publication March 28, 1932)

Because of the large number of patients in the University of Chicago Clinics showing high blood uric acid by the Koch ${ }^{1}$ modification of the Folin and Benedict methods using the Folin-Wu blood filtrate, it was decided to try a different method. The method which has seemed to to yield most satisfactory results is that described by Folin (1) in which he makes use of unlaked blood filtrate, a cyanide solution stabilized by means of urea, and a uric acid reagent free from phenol reagent. This method has been used for all uric acid determinations in the Medical department since May 1931, and has proved relatively satisfactory as a clinical method. The cyanide solution, which is kept at low temperature, retains its chromophoric power well, and when used with the uric acid reagent has produced no turbid solutions. It was, of course, necessary to determine a new series of normal blood uric acid values by this method, and while the results are not wholly free from unexplained high values (see Table V), it is believed that this method, as compared with the one formerly used, gives more satisfactory results.

For the purpose of comparison a few samples of blood were tested simultaneously for uric acid by the Koch modification formerly used (hereafter called "old method") and by the Folin method at present used. Two samples from a control patient, drawn on different days, gave 7.2 and $9.2 \mathrm{mgm}$. per $100 \mathrm{cc}$. by the old method and 3.9 and $3.8 \mathrm{mgm}$. per $100 \mathrm{cc}$. respectively by the new method. One sample from a patient with chronic gout gave 12.3 and $5.6 \mathrm{mgm}$. per $100 \mathrm{cc}$. by the old and new methods respectively. The uric acid in the blood of a patient with infectious arthritis was 5.3 and $2.1 \mathrm{mgm}$. per $100 \mathrm{cc}$. by the old and new methods respectively. There was thus a deviation in all instances in the same direction and to about the same degree, but there also seemed to be less variation in the results given by the method at present in use.

The first and most important consideration for diagnostic purposes in adopting a new method of determining the amount of uric acid in the venous blood was to find an upper limit for normal which would be reasonably satisfactory.

In Table I are a number of uric acid determinations made on diseasefree controls. It will be seen that in only two, Case 6, W. C., and Case

${ }^{1}$ Koch, F. C. Modification developed at University of Chicago. 
TABLE I

Disease-free controls

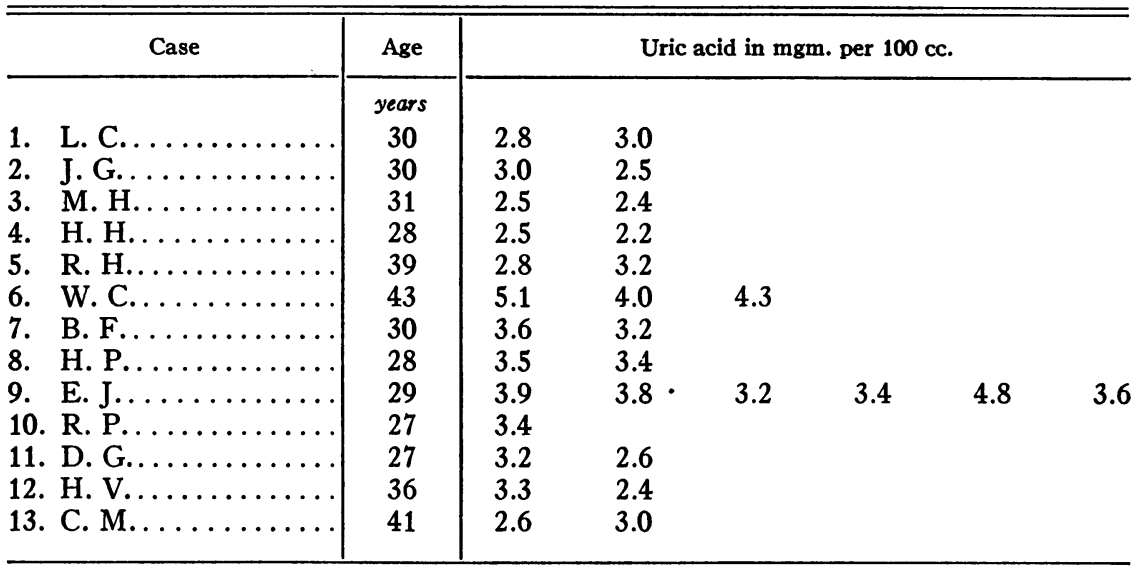

9, E. J., were any results found higher than $4 \mathrm{mgm}$. per cent. In one of these (Case 9) the high value obtained was only one of six, the others being normal, and this was interpreted as being of no significance. The other (Case 6) in which the uric acid value remained persistently above $4 \mathrm{mgm}$. was puzzling. In spite of the fact that this individual is apparently healthy in every way, and is one of the control cases, we are considering the uric acid values as abnormal.

In Table II are given a number of presumably normal uric acid readings and the clinical diagnosis in each case. It will be noted that in none of these is the uric acid above $4 \mathrm{mgm}$. per $100 \mathrm{cc}$. As a result this figure $-4 \mathrm{mgm}$. of uric acid per $100 \mathrm{cc}$. - is considered to be the usual upper limit of normal, subject to the qualifications discussed later.

The problem which prompted our interest in this study was that of gout. Because of several rather dramatic episodes in the diagnosis of this condition it became desirable to determine by the new method the uric acid levels occurring in this disease. Table III gives the amount of uric acid obtained in patients with gout. It was at first intended to attempt the differentiation of acute gout and chronic gout, but because of the tendency for one to shade into the other and because of the complications resulting from diet and medication this was deemed impracticable. It is noteworthy that the uric acid level is in most instances considerably above the upper limit of those believed to be normal as shown in Tables I and II. In none of these patients was the blood uric acid the sole basis of diagnosis, though we have found it an important aid.

It is well recognized (Peters and Van Slyke (2)) that the blood uric acid may be raised above normal in a number of conditions other than true gout. It has been reported that it may or may not be raised in nephritis with impaired kidney function (3), and that has been our ex- 
TABLE II

"Normal" blood uric acid

\begin{tabular}{|c|c|c|c|c|c|}
\hline Case & Diagnosis & Age & \multicolumn{3}{|c|}{$\begin{array}{l}\text { Uric acid in mgm. } \\
\text { per } 100 \mathrm{cc} .\end{array}$} \\
\hline 14. W. T.. & Cholelithiasis, colitis & $\begin{array}{c}\text { years } \\
54\end{array}$ & 2.9 & & \\
\hline 15. J. C... & None made, neurologic? & 19 & 3.4 & & \\
\hline 16. A. B.. & Postoperative adhesions & 69 & 3.4 & & \\
\hline 17. M. B.. & None made & 33 & 3.4 & & \\
\hline 18. F. C.... & Colitis & 45 & 1.6 & & \\
\hline 19. G. M.... & Carcinoma of pancreas, chronic cystitis & 76 & 2.2 & & \\
\hline 20. A. C... & Toxic liver necrosis & 48 & 1.9 & & \\
\hline 21. V. K... & Myasthenia gravis & 24 & 3.0 & & \\
\hline 22. V. D... & Duodenal ulcer, colitis & 48 & 3.0 & & \\
\hline 23. J. S.... & Hypertension, myocardial insufficiency & 51 & 2.9 & & \\
\hline 24. S. H.... & Maxillary sinusitis & 45 & 2.9 & & \\
\hline 25. M. O'D. & Carcinoma of thyroid & 72 & 1.0 & & \\
\hline 26. W. D... & Malignant obstructive jaundice & 57 & 1.5 & & \\
\hline 27. H. B... & None made & 47 & 2.4 & & \\
\hline 28. L. S.. . & None made & 34 & 3.8 & & \\
\hline 29. L. G... & Acute glomerulonephritis & 24 & 3.7 & & \\
\hline 30. C. M.. & Acute glomerulonephritis & 24 & 2.2 & & \\
\hline 31. E. M.. & Chronic glomerulonephritis & 23 & 2.3 & 2.1 & \\
\hline 32. A. D.. & Proliferative arthritis & 14 & 2.6 & & \\
\hline 33. W. C... & Proliferative arthritis & 64 & 3.1 & & \\
\hline 34. S. C... & Proliferative arthritis & 58 & 2.8 & 3.0 & \\
\hline 35. G. S... & Proliferative arthritis & 48 & 1.1 & & \\
\hline 36. J. A.. & Proliferative arthritis & 58 & 2.5 & & \\
\hline 37. M. A.. & Proliferative arthritis & 66 & 3.3 & & \\
\hline 38. H. D.. & Proliferative arthritis & 26 & 1.9 & 1.3 & 2.3 \\
\hline 39. F. H.. & Proliferative arthritis & 19 & 2.8 & & \\
\hline 40. J. B... & Proliferative arthritis & 52 & 2.1 & & \\
\hline 41. $\mathrm{H} . \mathrm{McC}$ & Proliferative arthritis & 35 & 3.3 & & \\
\hline 42. E. D... & Proliferative arthritis & 56 & 1.7 & & \\
\hline 43. E. O.. & Proliferative arthritis & 31 & 2.6 & & \\
\hline 44. S. B... & Proliferative arthritis & 44 & 3.2 & & \\
\hline 45. M. H.. & Proliferative arthritis & 32 & 3.7 & & \\
\hline 46. M. K.. & Traumatic internal derangement of knee & 26 & 2.6 & & \\
\hline 47. D. R.. & Acute sacroiliac strain & 32 & 2.8 & & \\
\hline 48. M. B.. & Rheumatic fever? & 21 & 2.1 & & \\
\hline 49. E. R.. & Radiculitis & 40 & 3.8 & & \\
\hline 50. E. S... & Rheumatic pains, colitis & 47 & 2.2 & & \\
\hline 51. J. B.. & Osteochondritis desicans & 29 & 2.6 & & \\
\hline 52. A. W.. & Degenerative arthritis, diabetes & 60 & 3.7 & & \\
\hline 53. K. J... & Degenerative arthritis & 70 & 2.9 & & \\
\hline 54. R. S.... & Acute rheumatic fever & 21 & 1.1 & & \\
\hline 55. E. F... & Degenerative arthritis & 70 & 3.0 & & \\
\hline 56. M. F.. & Degenerative arthritis & 65 & 3.3 & & \\
\hline 57. M. R.. & Degenerative arthritis, myxedema & 55 & 3.1 & & \\
\hline 58. N. H.. & Acute myositis, lues latens & 50 & 3.2 & & \\
\hline 59. B. J.. & Degenerative arthritis, lues latens & 43 & 3.4 & & \\
\hline
\end{tabular}


TABLE III

Gout

\begin{tabular}{|c|c|c|c|c|c|c|c|c|c|}
\hline Case & Age & \multicolumn{8}{|c|}{ Uric acid in mgm. per $100 \mathrm{cc}$. } \\
\hline 60. F. A. ......... & 50 & 5.2 & 5.2 & 4.9 & 5.0 & 4.8 & 7.7 & 4.5 & \\
\hline 61. J. P... & 48 & 4.4 & & & & & & & \\
\hline 62. A. S. . . . . . . & 66 & 4.0 & 6.1 & & & & & & \\
\hline 63. H. H........ & 48 & 3.9 & 4.2 & & & & & & \\
\hline 64. C. H. . . . . . & 46 & 4.6 & & & & & & & \\
\hline 65. F.S. . . . . . & 57 & 5.7 & 3.8 & & & & & & \\
\hline 66. D. D........ & 51 & 5.6 & 10.2 & 7.4 & & & & & \\
\hline 67. C. L. . . . . . . & 57 & 5.2 & 5.8 & 5.8 & 4.1 & 4.4 & 4.4 & 5.9 & \\
\hline 68. J. S... & 63 & 4.5 & 4.5 & 4.3 & 4.8 & 5.2 & 4.4 & 5.1 & 3.8 \\
\hline 69. D. F... & 62 & 4.2 & 4.3 & 3.9 & & & & & \\
\hline 70. H. H.... & 68 & 7.1 & & & & & & & \\
\hline 71. W. K.... & 50 & 5.4 & & & & & & & \\
\hline 72. S. L... & 45 & 4.9 & 4.7 & 3.6 & 4.3 & 5.0 & & & \\
\hline 73. F. W... & 48 & 8.3 & 4.9 & 5.2 & 6.1 & & & & \\
\hline 74. L. B... & 43 & 4.7 & 5.0 & & & & & & \\
\hline 75. Z. B... & 46 & 5.9 & & & & & & & \\
\hline 76. H. C.... & 35 & 6.7 & 5.6 & 5.9 & & & & & \\
\hline
\end{tabular}

perience. In Table IV are given the results in a series of patients where the increase in blood uric acid may be explained on a basis other than gout. In Case 85 where one determination was above the expected normal and the others were normal, the diagnosis was not clear and the possibility of visceral gout was considered. Because of the first result the patient was placed on a purine-poor diet and was living on this regime when the other three determinations were made. Many of the results given in Table IV are well within the range of gout, but two are higher than any we have yet found in gout.

It remains to include in Table $\mathrm{V}$ those high uric acids which cannot be explained by any information available to us. There have not been many of these. If more tests had been made on these patients it is possible that some of the high values obtained would have been shown to be

TABLE V

Unexplained high uric acids

\begin{tabular}{|c|c|c|c|}
\hline Case & Diagnosis & Age & Uric acid in mgm. per $100 \mathrm{cc}$. \\
\hline & & years & \\
\hline 90. M. H. & Metatarsal fracture & 26 & 5.0 \\
\hline 91. F. L..... & Obesity, cholecystitis & 50 & 4.1 \\
\hline 92. M. M.... & Migraine ? headaches & 48 & 4.1 \\
\hline 93. K. M.... & Proliferative arthritis & 59 & 4.4 \\
\hline 94. G. R.... . & Still's Disease (quiescent) & 14 & 5.8 \\
\hline 95. N. T.... & Proliferative arthritis & 68 & 4.5 \\
\hline 96. V. Z.... & Degenerative arthritis ? & 51 & 4.1 \\
\hline 97. E. E. & Tabes, mild diabetes & 60 & 4.2 \\
\hline
\end{tabular}




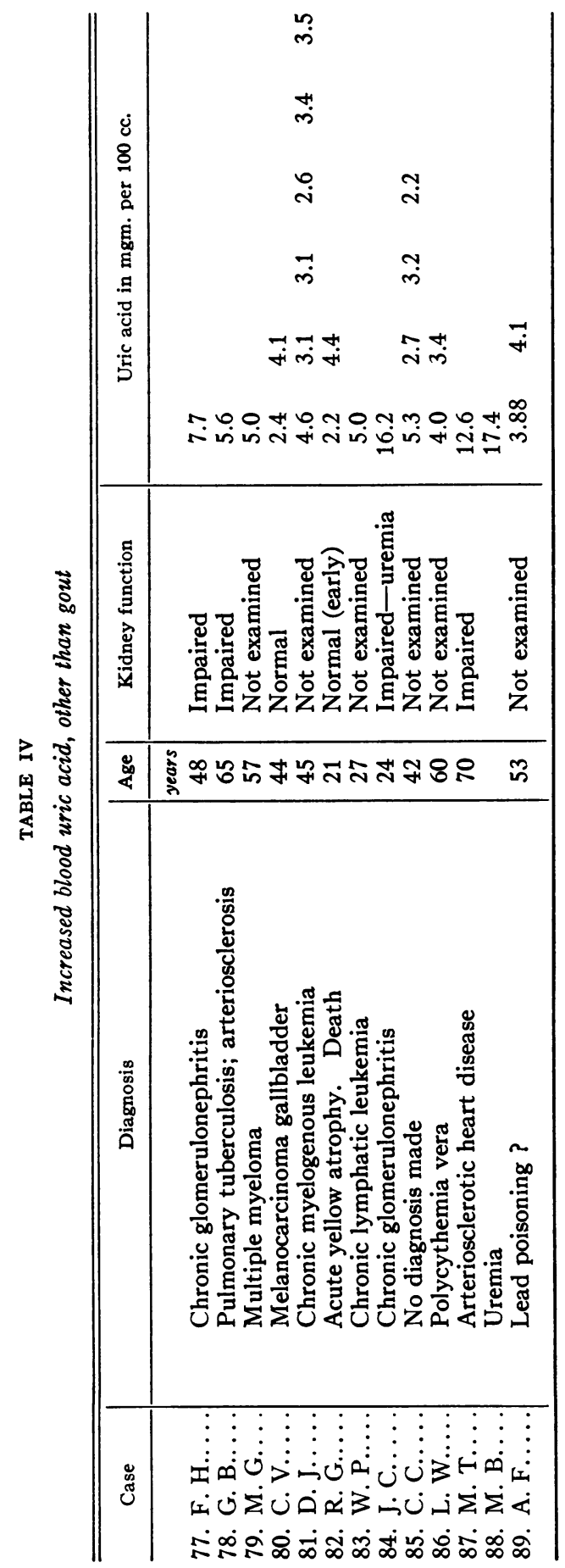


single aberrant tests and of no diagnostic significance. They must, however, be included as indicating flaws in the test as a diagnostic procedure.

\section{DISCUSSION}

With the discovery of the uric acid diathesis in gout, attention was focused on purine metabolism. Further studies have indicated that the relationship between uric acid retention and gout is not as simple as at first believed. Observers have reported considerable variation in the amount of.blood uric acid under normal conditions as well as in diseases other than gout. The significance of these findings is not as yet thoroughly understood. Although mention of gout in the contemporary American literature is unusual, it has been our experience to find the condition among Chicago patients with greater frequency than was anticipated. Whether a similar incidence of gout occurs in other parts of the country would be a matter of interest.

The amount of uric acid in the blood under normal and pathologic conditions is a matter of basic importance. The more accurately the determinations can be made the sooner will the understanding of purine metabolism approach scientific precision. By Folin's method, here in use, we believe that most, if not all, patients with gout will show blood uric acid values above a range which we accept as normal. The difficulty in diagnosis lies in distinguishing the higher values obtained in conditions other than gout. Most of such high values have occurred in the various conditions already known to be at times associated with high blood uric acid.

\section{BIBLIOGRAPHY}

1. Folin, O., J. Biol. Chem., 1930, lxxxvi, 173. Unlaked Blood as a Basis for Blood Analysis. J. Biol. Chem., 1930, lxxxvi, 179. An Improved Method for the Determination of Uric Acid in Blood.

2. Peters, J. P., and Van Slyke, D. D. Quantitative Clinical Chemistry. I. Williams and Wilkins, Baltimore, 1931, p. 408.

3. Johnston, C., J. Clin. Invest., 1931, ix, 555. The Relationship of Blood Uric Acid Content to the State of Renal Function in Nephritis. 